\title{
Effect of moisture content on the physical and mechanical properties of quinoa seeds
}

\author{
Khan Nadiya Jan*, Paramjit S. Panesar, and Sukhcharn Singh \\ Department of Food Engineering and Technology, Sant Longowal Institute of Engineering and Technology, Sangrur, \\ Punjab 148106, India
}

Received December 31, 2017; accepted June 29, 2018

\begin{abstract}
The study was conducted to compare the engineering properties of Indian quinoa seeds with increase in moisture content. Close dependency of the properties on moisture content was observed. Two germplasms of quinoa IC-411824 and EC-507739 were investigated. The results showed that the principal dimensions of EC-507739 were higher than those of IC-411824. With an increase in moisture mean values of true density increased from 993 to $1166 \mathrm{~kg} \mathrm{~m}^{-3}$ for EC-507739 and from 984 to $1097 \mathrm{~kg} \mathrm{~m}^{-3}$ for IC-411824. Coefficient of friction showed an increase of $16.29,16.00$, and $18.93 \%$ against glass, galvanized iron and wood respectively in case of IC-411824. However, for EC-507739 increase of 19.12, 22.73, and 23.21\% was observed against glass, galvanized iron and wood respectively. Mechanical properties were higher for EC-507739 than IC-411824 and decreased with increase in moisture content for both the varieties. Mechanical behavior of seed can be used in designing of grinding machines.

Keywords: Indian quinoa seeds, physical properties, rupture force, rupture energy
\end{abstract}

\section{INTRODUCTION}

The demand for quinoa is increasing worldwide because of its outstanding industrial, pharmacological and nutritional applications. It is quoted as 'chisaya mama' by the Incas because of serving as a complete diet (Van Etten et al., 1963). FAO puts quinoa among the crops intended to offer food security in the 21 st century because of its diversified tolerance to biotic and abiotic stresses, and a wide range of adaptability (FAO, 1998). The crop has high potential to grow in various stress conditions, like soil salinity, soil acidity, drought and frost, and it tolerates high temperatures up to $35^{\circ} \mathrm{C}$ (Jacobsen et al., 2003). Quinoa is non-allergenic as it is free from gluten. Because of low prolamine and glutamine contents, it can be beneficial for people suffering

*Corresponding author e-mail: khan14diya@gmail.com from celiac disease. Quinoa flour is used in making pancakes, bread, muffins, pastas, cookies and other foods (Jan et al., 2018). The major component of the grain is starch, which varies from $50-62 \%$, and is also responsible for its high demand (Jan et al., 2017 a, b and c).

Engineering properties at different moisture contents are required to design machines and storage facilities. For grains there is a notable growth in pressure on silo walls due to increased moisture content. Varying moisture content can also lead to flow problems in silos, such as arching, segregation and irregular flows (Kibar et al., 2010). The principal axial dimensions of grains are used for calculating the power requirement during milling, and for selecting sieve separators. The volume of kernels and surface area, which are important during aeration, the modelling of grain drying, heating and cooling, can also be calculated on the basis of the principal axial dimensions. Grain bulk density and true density can be useful in sizing storage facilities and grain hoppers, and they can affect the rate of heat and mass transfer of moisture during the aeration and drying. A greater resistance to water vapour escape during the drying process, offered by grain bed with low porosity, may lead to a higher power requirement to drive the aeration fans. The angle of repose gives the flow ability of grain which will be useful in hopper design, as the inclination angle of the hopper walls should be greater than the angle of repose, in order to ensure the continuous flow of materials by gravity. The friction coefficient is important in the design of conveyors because friction is necessary to hold the seeds to the conveying surface without slipping or sliding backward. The parameters determined by compression and shear tests are used for description of the grinding process.

(C) 2019 Institute of Agrophysics, Polish Academy of Sciences 
Hardness is a primary determinant of milling, end-use and baking quality. Reports on fracture characteristics of some small seeds, such as rape seeds, by Izli et al. (2009) are available. The dominant factor affecting the rupture force of the seed under quasi-static loading is moisture content (Saiedirad et al., 2008). Mechanical behaviour of quinoa seed is important in the design of grinding machines and can also be used to show the susceptibility of seeds to breakage during processing. These parameters of quinoa seed can provide the basis for an optimal design of relevant devices.

Despite the increasing interest in quinoa, little is known about its physical characteristics. Also, the production of quinoa in India is almost negligible, with no FAO data being currently available. Only few successful trials have been conducted for the cultivation of quinoa in India. A review of the literature has revealed that limited research has been conducted on the physical properties of quinoa seed, and no research data is available regarding its mechanical properties. In addition, the variety and environment have a huge impact on the dimensional, gravimetric and mechanical properties of seeds. Hence, the aim of this study was to investigate some engineering properties of quinoa seeds grown in India, as affected by the variety and moisture content variation. This may contribute to the knowledge about these seeds and ease the process of designing postharvest handling and processing machines.

\section{MATERIALS AND METHODS}

Two germplasms of Quinoa IC-411824 (V1) and EC-507739 (V2) used in this study were obtained from the National Bureau of Plant Genetic Resources (NBPGR), located in the Phagli area of Shimla, Himachal Pradesh. The seeds were then cultivated in December at an experimental farm of the Sant Longowal Institute of Engineering and Technology. The seeds were dried at room temperature and stored in plastic bags until being processed.

The seeds were cleaned in order to remove any foreign matter, such as dust, dirt, stones as well as broken and immature seeds. The moisture content of the samples was measured by drying them in an oven (Noomhorm and Verma, 1982). The seeds were conditioned to five different moisture contents, ranging from 5 to $25 \%$ (with an interval of $5 \%$ ). The original moisture content of the seeds was found to be $10 \%$. Samples below $10 \%$ were prepared by drying at $40^{\circ} \mathrm{C}$ in a convection air oven (Baumler et al., 2006). Samples above the moisture content of $10 \%$ were prepared by spraying pre-calculated amounts of distilled water, using the rewetting formula (Visvanathan et al., 1996):

$$
Q=\frac{A(b-a)}{(100-b)},
$$

where: $Q$ is the mass of added water $(\mathrm{kg}), A$ is the initial mass of the sample in $(\mathrm{kg}), a$ is the initial and $b$ is the desired moisture content of the sample.

The samples were then sealed in separate polyethylene bags for uniform distribution of moisture and kept at $5^{\circ} \mathrm{C}$ in a refrigerator for one week. The required quantity of seeds was taken out from the refrigerator and allowed to equilibrate to room temperature for almost one hour. The physical and mechanical properties of the seeds were determined at five moisture contents, i.e. 5, 10, 15, 20 and $25 \%$. Three replications of each sample were taken to avoid errors. Where desirable, five to ten replications were taken.

A grain micrometer with an accuracy of $0.02 \mathrm{~mm}$ was used to measure length $(L)$, width $(W)$ and thickness $(T)$. From the five fractions varying in moisture, samples of 50 seeds were drawn randomly and measured for $L, W$ and $T$ in ten replicates. The unit mass $(\mathrm{m}, \mathrm{g})$, was recorded by using an experimental balance with an accuracy of $\pm 0.001 \mathrm{~g}$. Other geometric properties were then determined from these three major linear dimensions.

The arithmetic mean diameter $\left(D_{a}\right)$ and the geometric mean diameter $\left(D_{g}\right)$, as the mean of the three dimensions, were calculated using the following expression (Bahnasawy, 2007):

$$
\begin{aligned}
& D_{a}=\frac{L+W+T}{3}, \\
& D_{g}=(L W T)^{1 / 3} .
\end{aligned}
$$

The surface area $(S)$ of seeds was calculated by following equation (McCabe et al., 1986):

$$
S=\pi D_{g}^{2} \text {. }
$$

Sphericity $(\varphi)$ was defined as the ratio of the surface area of the sphere, having the same volume as that of the grain, to the surface area of the grain. The higher the value of sphericity, the closer is the shape of the grain to a sphere. Sphericity was determined using the following equation (Mohsenin, 1986);

$$
\varphi=\frac{(L W T)^{1 / 3}}{L} .
$$

Bulk density $\left(\rho_{b}\right)$ is the ratio of the mass of the grain to its total volume. It was determined by filling a $100 \mathrm{ml}$ measuring cylinder with grains from a height of $15 \mathrm{~cm}$, and then by weighing the contents by means of a digital electronic balance (Shimadzu Corporation, Japan, AY120), having an accuracy of $\pm 0.001 \mathrm{~g}$. Bulk density for each replication was calculated using the following formula (Mohsenin, 1970):

$$
\rho_{b}=\frac{M s}{V s},
$$

where: $\rho_{b}$ is bulk density $\left(\mathrm{kg} \mathrm{m}^{-3}\right), M s$ is the mass of the sample $(\mathrm{kg})$, and $V_{S}$ is the volume occupied by the sample $\left(\mathrm{m}^{3}\right)$. 
True density $\left(\rho_{t}\right)$ is defined as the ratio of the mass of seeds to their true volume (Deshpande et al., 1993) and was determined using the toluene $\left(\mathrm{C}_{7} \mathrm{H}_{8}\right)$ displacement method. Toluene is mainly used instead of water as it is absorbed by seeds to a lesser extent. It also has a benefit of low surface tension and, hence, fills even shallow dips in seeds. The volume of toluene displaced was found by immersing a weighed quantity of seeds in the measured toluene. Approximately $10 \mathrm{~g}$ of seeds were immersed in $25 \mathrm{ml}$ toluene, placed in a graduated measuring cylinder. The amount of displaced toluene was recorded through the graduated cylinder scale. The true density was calculated using the equation as below:

$$
\rho_{t}=\frac{\text { weight of seeds }(\mathrm{kg})}{\text { rise in toluene level }\left(\mathrm{m}^{3}\right)},
$$

where: $\rho_{t}$ is true density $\left(\mathrm{kg} \mathrm{m}^{-3}\right)$.

The porosity $(\varepsilon)$ of bulk seed, which is the ratio of free space between grains to the total of bulk grains, was computed from the values of true density $\left(\rho_{t}\right)$ and bulk density $\left(\rho_{b}\right)$, using the following equation (Mohsenin, 1970):

$$
\varepsilon(\%)=\frac{\rho_{t}-\rho_{b}}{\rho_{t}} 100,
$$

where: $\varepsilon$ is porosity (\%).

For determining thousand seed weight, 100 seeds were selected randomly from each sample and weighed by means of an electronic balance (with an accuracy of $0.001 \mathrm{~g}$ ). The obtained value was then multiplied by 10 .

The angle of repose $(\theta)$ was determined from the height and diameter of the naturally formed heap of seeds in a hollow cylinder of a known diameter. The seeds were allowed to fall from a height of $15 \mathrm{~cm}$ on the cylinder for heap formation (Ozguven and Kubilay, 2004):

$$
\theta=\tan ^{-1}\left(\frac{2 H}{D}\right)
$$

where: $H$ and $D$ represent the height and diameter of heap, respectively.
The static coefficient of friction $(\mu)$ which affects the design of the processing machine was determined using three different contacting materials, i.e. galvanized iron, glass and plywood. These are the common materials for transportation, handling and storage of grains. The coefficient of friction was computed by filling a hollow cylinder of a known diameter and depth with grains and placing it on different surfaces. The resting surface of the cylinder was raised slowly until the cylinder, which had been filled with grains, just started to slide down (Razavi and Milani, 2006). The static coefficient of friction was calculated using the following formula:

$$
\mu=\tan \alpha,
$$

where: $\alpha$ is the angle of tilt $\left({ }^{\circ}\right)$.

The measurement of mechanical properties was carried out according to Sharma et al. (2009) with slight modifications. A Texture Analyzer (TA-HDi, Stable micro systems) was used to compress the seed at a pre-test speed $-1.5 \mathrm{~mm}$ $\mathrm{s}^{-1}$; test speed $-0.5 \mathrm{~mm} \mathrm{~s}^{-1}$; post-test speed $-10 \mathrm{~mm} \mathrm{~s}^{-1}$; test distance $-0.7 \mathrm{~mm}$; trigger type - auto; trigger force $0.20 \mathrm{~N}$; load cell $-50 \mathrm{~kg}$; and probe $-\mathrm{P} / 5$. Individual seeds were loaded between the probe $(\mathrm{P} / 5)$ and the base plate of the machine, and compressed at the pre-set conditions. The mechanical behaviour of quinoa seeds was expressed in terms of the initial cracking force, rupture force and rupture energy. For each test, ten samples were used from each moisture lot.

Statistical analysis was done by using Statistica-log software package, version 7 (M/s. StatSoft Inc., OK, USA). Significant differences were obtained by a one-way analysis of the variance test (ANOVA), followed by Duncan's multiple range test $(\mathrm{p}<0.05)$.

\section{RESULTS AND DISCUSSION}

Quinoa seed size distribution at the initial moisture content $(10 \%)$ is shown in Table 1. British Sieve Size (BSS) sieves, numbered $8,10,12,14$ and 18 , were used for the

\begin{tabular}{|c|c|c|c|c|c|c|}
\hline \multirow{2}{*}{ Variety } & \multirow{2}{*}{ Parameter } & \multirow{2}{*}{$\begin{array}{l}\text { Length } \\
(\mathrm{mm})\end{array}$} & \multirow{2}{*}{$\begin{array}{c}\text { Percent of sample } \\
\text { by number } \\
(\%)\end{array}$} & Length & Width & Thickness \\
\hline & & & & \multicolumn{3}{|c|}{$(\mathrm{mm})$} \\
\hline \multirow{4}{*}{$\mathrm{V} 1$} & Large & $>2.0$ & 25.9 & $2.03 \pm 0.03$ & $2.00 \pm 0.02$ & $1.00 \pm 0.03$ \\
\hline & Medium & $1.7-2.0$ & 69.9 & $1.87 \pm 0.04$ & $1.85 \pm 0.04$ & $0.93 \pm 0.01$ \\
\hline & Small & $<1.7$ & 3.2 & $1.68 \pm 0.07$ & $1.67 \pm 0.08$ & $0.85 \pm 0.03$ \\
\hline & Large & $>2.0$ & 26.4 & $2.10 \pm 0.03$ & $2.07 \pm 0.02$ & $1.07 \pm 0.01$ \\
\hline \multirow[t]{2}{*}{$\mathrm{V} 2$} & Medium & $1.7-2.0$ & 71.1 & $1.93 \pm 0.06$ & $1.91 \pm 0.07$ & $1.01 \pm 0.03$ \\
\hline & Small & $<1.7$ & 2.5 & $1.71 \pm 0.09$ & $1.69 \pm 0.10$ & $0.92 \pm 0.02$ \\
\hline
\end{tabular}
seed size distribution of a 1000 seed sample by number. The majority of quinoa seeds (about $71.1 \%$ of V2 and

Table 1. Size distribution of quinoa seeds with the moisture content of $10 \%$ 
$69.9 \%$ of V1) were medium sized (1.70 to $2.00 \mathrm{~mm}$ ). For $\mathrm{V} 2$, the sample $71.1 \%$ had a length between $1.7-2.0 \mathrm{~mm}$, referred to as medium fractions, $26.4 \%$ had a length higher than $2.0 \mathrm{~mm}$ (larger fractions), and the remaining $2.5 \%$ sample showed the seed size of less than $1.7 \mathrm{~mm}$ (smaller fractions). For V1, the medium fraction was about $69.9 \%$ with larger and smaller fraction being 25.9 and 3.2\%, respectively.

The effect of moisture content on the average values of the length and thickness of quinoa seeds is shown in Fig. 1. The length and width were approximately equal, and very small differences existed, as was also reported by Vilche et al. (2003). The length and thickness of both varieties were significantly different $(\mathrm{p}<0.05)$, with $\mathrm{V} 2$ being wider and thicker than V1. Dimensions of both varieties increased linearly with an increase in moisture content. The length of the seeds increased from 1.81 to $2.09 \mathrm{~mm}$ for $\mathrm{V} 1$, and from

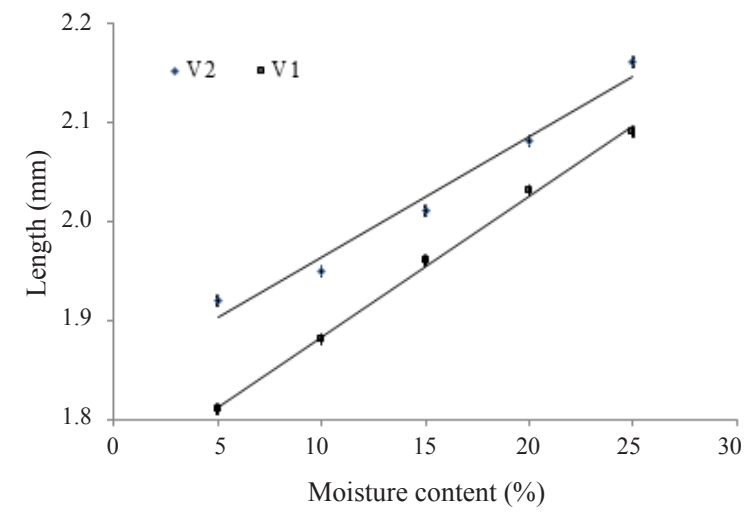

1.92 to $2.16 \mathrm{~mm}$ for $\mathrm{V} 2$, whereas thickness increased from for 0.79 to 0.95 for $\mathrm{V} 1$, and from 0.92 to $1.07 \mathrm{~mm}$ for V2, with an increase in moisture content from 5 to $25 \%$. The dimensions of the quinoa seeds were observed to fall within the range observed for rapeseed (Izli et al., 2009) and quinoa from Argentina (Vilche et al., 2003), but they were higher than those of amaranth seeds (Abalone et al., 2004). The increase in moisture content showed a significant effect $(p<0.05)$ on the length and thickness of both varieties, with a more pronounced effect on length than on thickness. A similar linear increasing trend of grain dimensions, with an increase in moisture content, is reported in the literature (Bamgboye and Adejumo, 2009; Vilche et al., 2003; Abalone et al., 2004). Dimensions of the seeds are of paramount importance in determining the aperture size of the machine to process the seed. Apart from that, the dimensions could be useful in determining the shape of the seed.

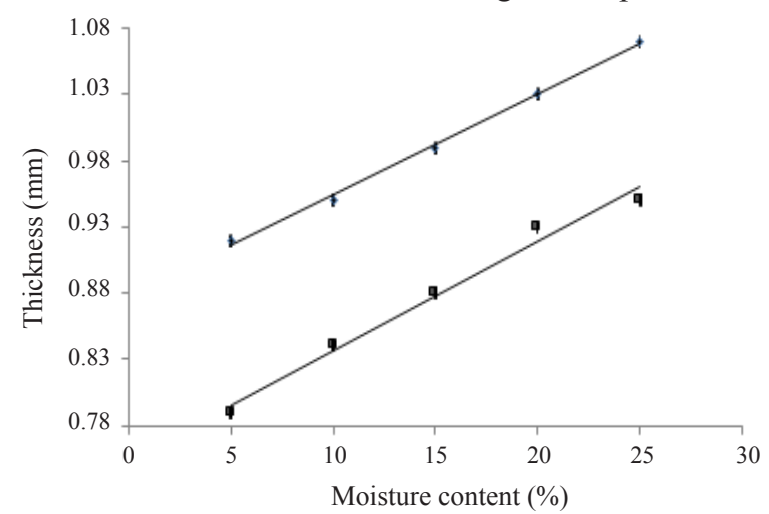

Fig. 1. Effect of moisture content on: $a$ - length, and $b$ - thickness of quinoa seeds.

T a b l e 2. Effect of moisture content on geometric properties of quinoa seeds

\begin{tabular}{|c|c|c|c|c|c|}
\hline Variety & $\begin{array}{c}\text { Moisture content } \\
(\%)\end{array}$ & $\begin{array}{c}\text { Geometric mean } \\
\text { diameter }(\mathrm{mm})\end{array}$ & $\begin{array}{l}\text { Arithmetic mean } \\
\text { diameter }(\mathrm{mm})\end{array}$ & Sphericity & $\begin{array}{l}\text { Surface area } \\
\qquad\left(\mathrm{mm}^{2}\right)\end{array}$ \\
\hline \multirow{5}{*}{ V1 } & 5 & $1.37 \pm 0.03 \mathrm{eB}$ & $1.47 \pm 0.03 \mathrm{eB}$ & $0.760 \pm 0.01 \mathrm{aB}$ & $5.9 \pm 0.26 \mathrm{cB}$ \\
\hline & 10 & $1.43 \pm 0.02 \mathrm{~dB}$ & $1.53 \pm 0.02 \mathrm{~dB}$ & $0.764 \pm 0.01 \mathrm{aB}$ & $6.46 \pm 0.18 \mathrm{bB}$ \\
\hline & 15 & $1.50 \pm 0.03 \mathrm{cB}$ & $1.60 \pm 0.03 \mathrm{cB}$ & $0.766 \pm 0.01 \mathrm{aB}$ & $7.10 \pm 0.25 \mathrm{aB}$ \\
\hline & 20 & $1.56 \pm 0.01 \mathrm{bB}$ & $1.66 \pm 0.01 \mathrm{bB}$ & $0.769 \pm 0.01 \mathrm{aB}$ & $7.68 \pm 0.14 \mathrm{aB}$ \\
\hline & 25 & $1.60 \pm 0.02 \mathrm{aB}$ & $1.71 \pm 0.02 \mathrm{aB}$ & $0.770 \pm 0.01 \mathrm{aB}$ & $8.08 \pm 0.21 \mathrm{aB}$ \\
\hline \multirow{5}{*}{$\mathrm{V} 2$} & 5 & $1.50 \pm 0.01 \mathrm{eA}$ & $1.58 \pm 0.01 \mathrm{eA}$ & $0.782 \pm 0.01 \mathrm{aA}$ & $7.06 \pm 0.09 \mathrm{eA}$ \\
\hline & 10 & $1.54 \pm 0.01 \mathrm{dA}$ & $1.62 \pm 0.01 \mathrm{dA}$ & $0.786 \pm 0.01 \mathrm{aA}$ & $7.42 \pm 0.14 \mathrm{dA}$ \\
\hline & 15 & $1.58 \pm 0.01 \mathrm{cA}$ & $1.67 \pm 0.01 \mathrm{cA}$ & $0.789 \pm 0.01 \mathrm{aA}$ & $7.87 \pm 0.12 \mathrm{cA}$ \\
\hline & 20 & $1.65 \pm 0.01 \mathrm{bA}$ & $1.73 \pm 0.02 \mathrm{bA}$ & $0.790 \pm 0.01 \mathrm{aA}$ & $8.51 \pm 0.14 \mathrm{bA}$ \\
\hline & 25 & $1.71 \pm 0.02 \mathrm{aA}$ & $1.80 \pm 0.02 \mathrm{aA}$ & $0.790 \pm 0.01 \mathrm{aA}$ & $9.17 \pm 0.23 \mathrm{aA}$ \\
\hline
\end{tabular}

Values followed by different lower-case letters in each row are significantly different $(\mathrm{p}<0.05)$ among the varying moisture contents of the same sample. Values followed by different upper-case letters within rows are significantly $(\mathrm{p}<0.05)$ different among the varieties. Lower-case letters show the effect of moisture content only within the variety and the upper case letters show the varietal effect only. 
Table 3. Effect of moisture content on the gravimetric properties and the angle of repose of quinoa seeds

\begin{tabular}{|c|c|c|c|c|c|c|}
\hline Variety & $\begin{array}{l}\text { Moisture } \\
\text { content }\end{array}$ & $\begin{array}{l}\text { Bulk density } \\
\quad\left(\mathrm{kg} \mathrm{m}^{-3}\right)\end{array}$ & $\begin{array}{l}\text { True density } \\
\qquad\left(\mathrm{kg} \mathrm{m}^{-3}\right)\end{array}$ & $\begin{array}{c}\text { Porosity } \\
(\%)\end{array}$ & $\begin{array}{c}\text { Thousand seed } \\
\text { weight }(\mathrm{g})\end{array}$ & $\begin{array}{c}\text { Angle of repose } \\
\left({ }^{\circ}\right)\end{array}$ \\
\hline \multirow{5}{*}{ V1 } & 5 & $701 \pm 1.01 \mathrm{aB}$ & $984 \pm 4.11 \mathrm{~dB}$ & $28.85 \pm 0.26 \mathrm{eB}$ & $2.54 \pm 0.01 \mathrm{eB}$ & $19.07 \pm 0.14 \mathrm{eA}$ \\
\hline & 10 & $686 \pm 1.89 \mathrm{bB}$ & $1002 \pm 4.53 \mathrm{cB}$ & $31.51 \pm 0.47 \mathrm{~dB}$ & $2.65 \pm 0.01 \mathrm{~dB}$ & $20.99 \pm 0.18 \mathrm{dA}$ \\
\hline & 15 & $665 \pm 1.10 \mathrm{cB}$ & $1030 \pm 4.93 \mathrm{bB}$ & $35.43 \pm 0.36 \mathrm{cB}$ & $2.79 \pm 0.02 \mathrm{cB}$ & $23.84 \pm 0.15 \mathrm{cA}$ \\
\hline & 20 & $652 \pm 1.28 \mathrm{~dB}$ & $1058 \pm 4.99 \mathrm{aB}$ & $38.37 \pm 0.30 \mathrm{bB}$ & $2.91 \pm 0.03 \mathrm{bB}$ & $24.78 \pm 0.19 b A$ \\
\hline & 25 & $645 \pm 1.01 \mathrm{eB}$ & $1097 \pm 4.67 \mathrm{aB}$ & $43.20 \pm 0.40 \mathrm{aB}$ & $3.03 \pm 0.01 \mathrm{aB}$ & $26.57 \pm 0.28 \mathrm{aA}$ \\
\hline \multirow{5}{*}{$\mathrm{V} 2$} & 5 & $721 \pm 1.02 \mathrm{aA}$ & $993 \pm 4.18 \mathrm{dA}$ & $27.47 \pm 0.30 \mathrm{eA}$ & $2.61 \pm 0.02 \mathrm{eA}$ & $15.05 \pm 0.14 \mathrm{eB}$ \\
\hline & 10 & $708 \pm 1.15 \mathrm{bA}$ & $1023 \pm 4.70 \mathrm{cA}$ & $30.79 \pm 0.34 \mathrm{dA}$ & $2.72 \pm 0.01 \mathrm{dA}$ & $16.08 \pm 0.18 \mathrm{~dB}$ \\
\hline & 15 & $688 \pm 1.82 \mathrm{CA}$ & $1048 \pm 5.80 \mathrm{bA}$ & $34.36 \pm 0.41 \mathrm{cA}$ & $2.88 \pm 0.02 \mathrm{cA}$ & $18.09 \pm 0.15 \mathrm{cB}$ \\
\hline & 20 & $679 \pm 1.02 \mathrm{dA}$ & $1096 \pm 5.36 \mathrm{aA}$ & $38.09 \pm 0.36 \mathrm{bA}$ & $2.99 \pm 0.01 \mathrm{bA}$ & $20.99 \pm 0.19 b B$ \\
\hline & 25 & $670 \pm 1.08 \mathrm{eA}$ & $1166 \pm 5.83 \mathrm{aA}$ & $42.68 \pm 0.38 \mathrm{aA}$ & $3.13 \pm 0.01 \mathrm{aA}$ & $23.86 \pm 0.28 \mathrm{aB}$ \\
\hline
\end{tabular}

Explanations as in Table 2.

The arithmetic mean diameter and the geometric mean diameter of V2 were greater than those of V1 (Table 2). These diameters grew with an increase in moisture content ( 5 to $25 \%$ ) for both varieties. The arithmetic mean diameter showed an increase of $13.92 \%$ for $\mathrm{V} 2$, and $16.33 \%$ for V1. In the case of the geometric mean diameter, an increase of $14 \%$ was observed for V2 and $16.79 \%$ for V1. There was a significant effect of a moisture content increase on the arithmetic mean diameter and the geometric mean diameter $(p<0.05)$. The increase in the arithmetic mean diameter, the geometric mean diameter and sphericity, with increasing moisture content, might be attributed to a growth in the principle dimensions of the seed. The geometric mean diameter obtained can be used to determine the volume and sphericity of the seed theoretically. The results are in agreement with the increasing trend shown by Izli et al. (2009) for rapeseed seeds, and by Abalone et al. (2004) for amaranth seeds.

The variation in the grain surface area with moisture content is shown in Table 2. The surface area of V2 varied from 7.06 to $9.17 \mathrm{~mm}^{2}$, and for V2 varied from 5.9 to $8.08 \mathrm{~mm}^{2}$. It was also found to increase by $36.95 \%$ for $\mathrm{V} 1$ and $29.89 \%$ for V2. The surface area of both varieties was significantly influenced by the increased moisture content $(\mathrm{p}<0.05)$. A similar trend for the surface area was observed by Izli et al. (2009) for rapeseed. The sphericity of quinoa seeds varied from 0.760 to 0.770 for V1, increasing by $1.32 \%$, and from 0.782 to 0.790 for $\mathrm{V} 2$, showing an increase of $1.02 \%$. This shows that seeds can slide on flat surfaces easily. A similar linear increasing trend in sphericity has been reported for roselle and sunflower seeds (Bamgboye and Adejumo, 2009; Malik and Saini, 2016).

With an increase in moisture content, the values for bulk density were observed to decrease from 721 to $670 \mathrm{~kg}$ $\mathrm{m}^{-3}$ for $\mathrm{V} 2$, and from 701 to $645 \mathrm{~kg} \mathrm{~m}^{-3}$ for V1, as shown in Table 3 . This decrease could be attributed to the volumetric expansion of the seed and pore spaces which became proportionally greater on moisture absorption. Bulk density showed the percentage variation of $7.99 \%$ for $\mathrm{V} 1$, and $7.07 \%$ for $\mathrm{V} 2$, in the given moisture range ( 5 to $25 \%$ ). V2 exhibited higher bulk density than V2 which may be due to larger size of V1 resulting in higher mass than for V1. Bulk density was significantly $(\mathrm{p}<0.05)$ influenced by the variety and increasing moisture content. The negative linear relationship of bulk density with moisture content was also observed by various other researchers, including Izli et al. (2009) for rapeseeds and Altuntaş et al. (2005) for fenugreek seeds.

True density increased from 993 to $1166 \mathrm{~kg} \mathrm{~m}^{-3}$ for $\mathrm{V} 2$, and from 984 to $1097 \mathrm{~kg} \mathrm{~m}^{-3}$ for $\mathrm{V} 1$. The percentage increase of 17.42 and $11.48 \%$ was observed for $\mathrm{V} 2$ and $\mathrm{V} 1$, respectively, with an increase in moisture content, as shown in Table 3. V1 exhibited lower true density than V2 which may be due to its dimensions resulting in a smaller increase in true volume. Differences in true density of the two varieties can also be due to variations in their volume, structure and weight decrease or increase characteristics. True density was significantly $(\mathrm{p}<0.05)$ influenced by the variety and increased moisture content. The increase in 
Table 4. Effect of moisture content on the mechanical properties of quinoa seeds

\begin{tabular}{|c|c|c|c|c|}
\hline Variety & Moisture content & $\begin{array}{l}\text { Initial cracking force } \\
(\mathrm{N})\end{array}$ & $\begin{array}{l}\text { Rupture force } \\
\text { (N) }\end{array}$ & $\begin{array}{l}\text { Rupture energy } \\
\text { (Ns) }\end{array}$ \\
\hline \multirow{5}{*}{ V1 } & 5 & $41.70 \pm 2.18 \mathrm{aB}$ & $51.97 \pm 1.67 \mathrm{aB}$ & $35.97 \pm 1.25 \mathrm{aB}$ \\
\hline & 10 & $38.95 \pm 4.18 \mathrm{abB}$ & $47.17 \pm 2.24 \mathrm{bB}$ & $33.08 \pm 1.66 \mathrm{abB}$ \\
\hline & 15 & $37.13 \pm 3.10 \mathrm{bcB}$ & $43.17 \pm 2.04 \mathrm{cB}$ & $30.03 \pm 2.06 \mathrm{bcB}$ \\
\hline & 20 & $34.47 \pm 2.84 \mathrm{cdB}$ & $41.07 \pm 1.16 \mathrm{cdB}$ & $27.11 \pm 1.85 \mathrm{cdB}$ \\
\hline & 25 & $31.06 \pm 4.10 \mathrm{~dB}$ & $39.20 \pm 1.15 \mathrm{~dB}$ & $24.99 \pm 1.97 \mathrm{bdB}$ \\
\hline \multirow{5}{*}{$\mathrm{V} 2$} & 5 & $47.50 \pm 2.03 \mathrm{aA}$ & $56.29 \pm 2.05 \mathrm{aA}$ & $40.94 \pm 2.04 \mathrm{aA}$ \\
\hline & 10 & $44.61 \pm 2.07 \mathrm{abA}$ & $52.35 \pm 1.89 \mathrm{bA}$ & $37.53 \pm 2.02 \mathrm{abA}$ \\
\hline & 15 & $42.93 \pm 2.91 \mathrm{bA}$ & $47.84 \pm 1.97 \mathrm{cA}$ & $34.83 \pm 1.93 \mathrm{bcA}$ \\
\hline & 20 & $40.37 \pm 2.27 \mathrm{bcA}$ & $44.91 \pm 1.94 \mathrm{cdA}$ & $32.16 \pm 2.37 \mathrm{cdA}$ \\
\hline & 25 & $36.99 \pm 1.69 \mathrm{cA}$ & $41.99 \pm 1.02 \mathrm{cdA}$ & $30.09 \pm 1.35 \mathrm{dA}$ \\
\hline
\end{tabular}

Explanations as in Table 2.

true density, with an increase in moisture content, might be attributed to the relatively lower true volume, as compared to the corresponding mass of the kernel attained due to water adsorption. A similar trend was observed by Kingsly et al. (2006) for pomegranate seeds, and by Vilche et al. (2003) for quinoa seeds from Argentina.

The porosity of the seed increased linearly from 27.47 to $42.68 \%$ for $\mathrm{V} 2$, and from 28.58 to $43.20 \%$ for $\mathrm{V} 1$, with an increase in the moisture content from 5 to $25 \%$, as shown in Table 3. This variation may be attributed to its dependence on the bulk and true densities of the seed. The effect of variety and increased moisture content on porosity was significant $(\mathrm{p}<0.05)$. At any moisture level, the porosity values for both quinoa varieties were lower than those for nigella seeds (Singh et al., 2015). The results for porosity are in accordance with those presented for amaranth and quinoa seeds (Abalone et al., 2004; Vilche et al., 2003).

The variation of the thousand seed weight (TSW) with moisture content is shown in Table 3. It increased linearly from 2.54 to $3.03 \mathrm{~g}$ for $\mathrm{V} 1$, and from 2.61 to $3.13 \mathrm{~g}$ for V2. Thus, an increase of 19.92 and $19.29 \%$ was observed for $\mathrm{V} 2$ and $\mathrm{V} 1$, respectively, with an increase in moisture content from 5 to $25 \%$. The effect of variety and increasing moisture content on the thousand seed weight was significant $(\mathrm{p}<0.05)$. A similar increasing trend in the thousand seed weight was found by Izli et al. (2009) for rapeseeds, and by Malik and Saini (2016) for sunflower seeds.

The angle of repose increased from 19.07 to $26.57^{\circ}$ for $\mathrm{V} 1$, and from 15.05 to $23.86^{\circ}$ for $\mathrm{V} 2$, as shown in Table 3. The lower angle of repose of $\mathrm{V} 2$ seeds represents a smoother outer surface, hence the easiness to slide on each other in comparison to V1. There was a significant influence of increasing moisture content on the angle of repose $(p<0.05)$. The angle of repose indicates the cohe- sion among the individual units of the material. The higher the cohesion, the higher the angle of repose. This increasing trend of the angle of repose depending on moisture content occurs because the surface layer of moisture surrounding the particle holds the aggregate of seeds together by the surface tension. Similar results were found by Singh et al. (2015) for nigella seeds. A low angle of repose makes the seeds spread out wider on a plane surface, compared to a high angle of repose. A low angle of repose is often advisable during belt conveying while a high angle of repose is more desirable when unloading onto a horizontal surface.

The static coefficients of friction of quinoa seeds on three surfaces (plywood, glass and galvanized iron) against moisture content in the range of $5-25 \%$ are presented in Fig. 2. The static coefficient of friction of both quinoa varieties showed the significant difference $(p<0.05)$, with V2 showing a lower static coefficient of friction than V1. The lower coefficient of friction of $\mathrm{V} 2$ is in agreement with its lower angle of repose. The coefficient of friction increased linearly with an increase in moisture content for both varieties, against all contact surfaces. An increase of $16.29,16.00$, and $18.93 \%$ was observed against glass, galvanized iron and wood, respectively, for V1. However, for V2, an increase of 19.12, 22.73, and $23.21 \%$ was observed against glass, galvanized iron and wood, respectively. The increased friction coefficient at a higher moisture content may be due to the moisture present in grains, offering an increased cohesive force on the contact surface. Among various contact surfaces, plywood offered the highest coefficient of static friction, followed by galvanized iron and glass, which may be due to smoother surfaces of glass and galvanized iron, in comparison to plywood. A similar trend was reported by Izli et al. (2009) for rapeseed. 

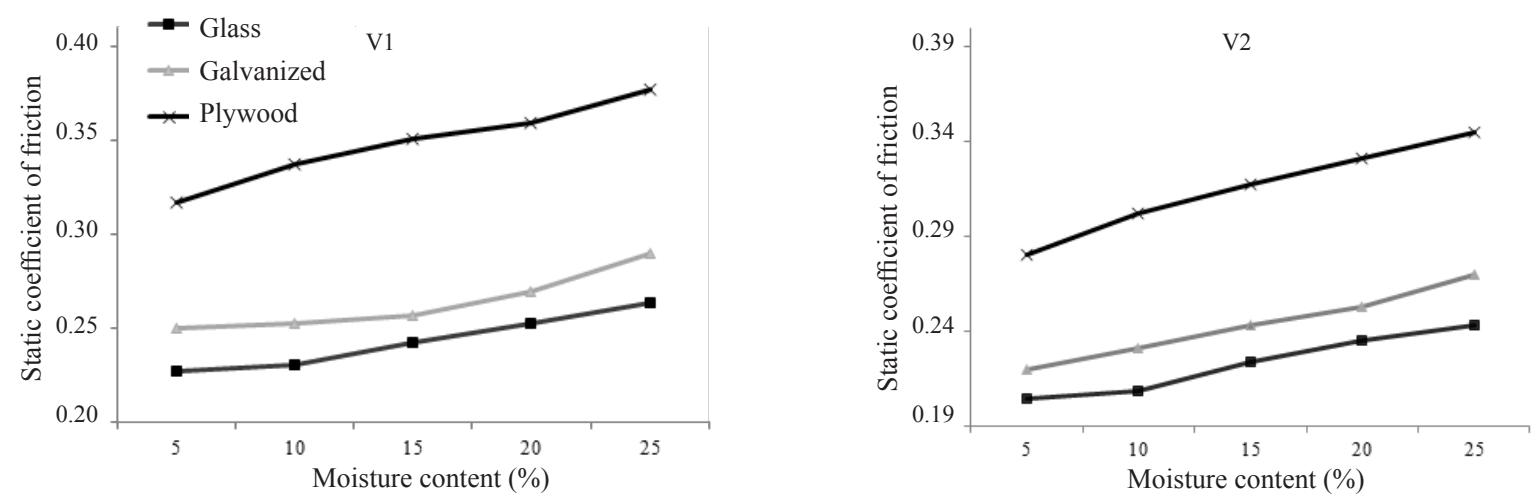

Fig. 2. Effect of moisture content on the static coefficient of friction of quinoa seeds against various contact surfaces.

The variation of the initial cracking force of quinoa seed at different moisture contents is given in Table 4. The initial cracking force of V2 was greater than that of V1, which may be due to a slightly larger size of V2. The initial cracking force for seeds decreased linearly from 47.50 to 36.99 $\mathrm{N}(\mathrm{p}<0.05)$ for $\mathrm{V} 2$, and from 41.70 to $31.06 \mathrm{~N}$ for $\mathrm{V} 1$, with an increase in moisture content. This decreasing trend might be possibly due to a gradual change in the integrity of the cellular matrix. A similar negative linear relationship trend of the cracking force was also observed by Malik and Saini (2016) for sunflower seeds, and by Joshi et al. (1993) for pumpkin seeds.

The average rupture force of quinoa seeds at different moisture contents is given in Table 4. The rupture force for the seeds significantly decreased from 56.29 to $41.99 \mathrm{~N}$ for $\mathrm{V} 2$, and from 51.97 to $39.20 \mathrm{~N}$ for V1, with an increase in moisture content from $5 \%$ to $25 \%(\mathrm{p}<0.05)$. Saiedirad et al., 2008 also showed the decreasing trend of the rupture force, with an increase in moisture content, for cumin seeds. The higher rupture forces were obtained at lower levels of moisture content due to hard texture of the seed at lower moisture contents. With a low moisture content, only the outer coating absorbed moisture, whereas an increase in moisture resulted in the gradual absorption of moisture by the inner core.

The variation of the average rupture energy $\left(E_{r}\right)$ of quinoa seeds at different moisture contents is presented in Table 4. The average rupture energy followed a linear decreasing trend, with an increase in the moisture level in all the cases. Rupture energy decreased from 40.94 to 30.09 Ns $(\mathrm{p}<0.05)$ for V2, and from 35.97 to 24.99 Ns for V1. A similar decreasing trend of rupture energy with and increasing moisture content was observed by Balasubramanian et al. (2012) for coriander.

\section{CONCLUSIONS}

The following conclusions have been formulated based on investigations of the moisture-dependent physical and mechanical properties of quinoa seeds, with moisture content ranging from 5 to $25 \%$.
1. Moisture content showed a significant effect on all engineering properties of quinoa, except sphericity.

2. Thousand seed weight, true density, the angle of repose and the coefficient of friction for quinoa seeds showed positive correlations with an increase in moisture content.

3. Bulk density, the initial cracking force, rupture energy and rupture forces showed negative correlations with an increase in moisture content.

4. At all moisture contents, plywood showed the highest friction coefficient, followed by galvanized iron and glass.

5. The mechanical properties of the quinoa varieties within the given moisture range revealed that variety V2 was more resistant to fracture. Furthermore, resistance to fracture for both varieties decreased with an increase in moisture content.

\section{ACKNOWLEDGEMENT}

The authors are thankful to Dr. J.C. Rana, Head of the Division National Bureau of Plant Genetic Resources (NBPGR), Shimla, Himachal Pradesh for providing germplasms. Funding for this research was provided by the TEQIP Sant Longowal Institute of Engineering and Technology.

Conflict of interest: The Authors do not declare conflict of interest.

\section{REFERENCES}

Abalone R., Cassinera A., Gastón A., and Lara M.A., 2004. Some physical properties of Amarnath seeds. Biosyst. Eng., 89(1), 109-117.

Altuntaş E., Özgöz E., and Taşer Ö.F. 2005. Some physical properties of fenugreek (Trigonella foenum-graceum L.) seeds. J. Food Eng., 71(1), 37-43.

Bahnasawy A.H., 2007. Some physical and mechanical properties of garlic. Int. J. Food Eng., 3, 1-18.

Balasubramanian S., Singh K.K., and Kumar R., 2012. Physical properties of coriander seeds at different moisture content. Int. Agrophys., 26, 419-422. 
Bamgboye A.I. and Adejumo O.I., 2009. Physical properties of roselle (Hibiscus sabdeferra) seeds. Agric. Eng. Int. CIGR E-journal. Manuscript 1154, XI, 1-13.

Baumler E., Cuniberti A., Nolasco S.M., and Riccobene I.C., 2006. Moisture dependent physical and compression properties of safflower seed. J. Food Eng., 72(2), 134-140.

Deshpande S.O., Bal S., and Ojha T.P., 1993. Physical properties of soybean. J. Agr. Eng. Res., 56, 89-98.

Food and Agriculture Organization 1998, FAO. Underutilized Andean Food Crops. FAO, Rome, Italy.

Izli N., Unal H., and Sincik M., 2009. Physical and mechanical properties of rapeseed at different moisture content. Int. Agrophys., 23, 137-145.

Jacobsen S.E., Mujica A., and Jensen C.R., 2003. The resistance of quinoa (Chenopodium quinoa Willd.) to adverse abiotic factors. Food Rev. Int., 19, 99-109.

Jan K.N., Panesar P.S., Rana J.C., and Singh S., 2017a. Structural, thermal and rheological properties of starches isolated from Indian quinoa varieties. Int. J. Biol. Macromol., 102, 315-322.

Jan K.N., Panesar P.S., and Singh S., 2017b. Process standardization for isolation of quinoa starch and its characterization in comparison with other starches. J. Food Meas Charact., 11(4), 1919-1927.

Jan K.N., Panesar P.S., and Singh S., 2017c. Textural, in vitro antioxidant activity and sensory characteristics of cookies made from blends of wheat-quinoa grown in India. J. Food Process Preserv., 42(3), e13542.

Jan K.N., Panesar P.S., and Singh S., 2018. Optimization of antioxidant activity, textural and sensory characteristics of gluten-free cookies made from whole indian quinoa flour. LWT, 93, 573-582.

Joshi D.C., Das S.K., and Mukherjee R.K., 1993. Physical properties of pumpkin seeds. J. Agr. Eng. Res., 54, 219-229.

Kibar H., Öztürk T., and Esen B., 2010. The effect of moisture content on physical and mechanical properties of rice (Oryza sativa L.). Spanish J. Agric. Res., 8, 741-749.

Kingsly A.R.P., Singh D.B., Manikantan M.R., and Jaib R.K., 2006. Moisture dependent physical properties of dried pomegranate seed (anaradana). J. Food Eng., 75, 492-496.
Malik M.A. and Saini C.S., 2016. Engineering properties of sunflower seed: Effect of dehulling and moisture content. Cogent Food Agric., 2(1), 1145783, 1-11.

McCabe W.L., Smith J.C., and Harriot P., 1986. Unit Operations of Chemical Engineering. McGraw-Hill, New York, USA.

Mohsenin N.N., 1970. Physical properties of plant and animal materials New York: Gordon and Breach Science Publishers.

Mohsenin N.N., 1986. Physical Properties of Plant and Animal Materials. Gordon and Breach Press, New York, USA.

Noomhorm A. and Verma L.R., 1982. A comparison of microwave, air oven and moisture meters with the standard method for rough rice moisture determination. Trans. ASAE, 25(5), 1464-1470.

Ozguven F. and Kubilay V., 2004. Some physical, mechanical and aerodynamic properties of pine (Pinus pinea) nuts. J. Food Eng., 68(2), 191-196.

Razavi S. and Milani E., 2006. Some physical properties of the watermelon seeds. African J. Agric. Res., 13, 65-69.

Saiedirad M.H., Tabatabaeefar A., Borghei A., Mirsalehi M., Badii F., and Varnamkhasti M.G., 2008. Effects of moisture content, seed size, loading rate and seed orientation on force and energy required for fracturing cumin seed (Cuminum cyminum L.) under quasi-static loading. J. Food Eng., 86, 565-572.

Sharma R., Sogi D.S., and Saxena D.C., 2009. Dehulling performance and textural characteristics of unshelled and shelled sunflower (Helianthus annuus L.) seeds. J. Food Eng., 92, 1-7.

Singh R.K., Vishwakarma R.K., Vishal M.K., Singh S.K., and Saharan V.K., 2015. Moisture dependent physical properties of nigella seeds. Afr. J. Agric. Res., 10(2), 58-66.

Van Etten C.H., Miller R.W., Wolff I.A., and Jones Q., 1963. Amino acid composition of seeds from 200 angiosperm plants. J. Agric. Food Chem., 11, 399-410.

Vilche C., Gely M., and Santalla E., 2003. Physical properties of quinoa seeds. Biosyst. Eng., 86 (1), 59-65.

Visvanathan R., Palanisamy P.T., Gothandapani L., and Sreenarayanan V.V., 1996. Physical properties of neem nut. J. Agr. Eng. Res., 63, 19-26. 